\title{
Inhibition of $5 \alpha$-reductase alters pregnane metabolism in the late pregnant mare
}

\author{
Michelle A A Wynn¹, Barry A Ball ${ }^{1}$, Erin Legacki², Alan Conley², Shavahn Loux , John May ${ }^{3}$, \\ Alejandro Esteller-Vico ${ }^{1}$, Scott Stanley ${ }^{4}$, Kirsten Scoggin ${ }^{1}$, Edward Squires ${ }^{1}$ and Mats Troedsson ${ }^{1}$ \\ ${ }^{1}$ Gluck Equine Research Center, Department of Veterinary Science, University of Kentucky, Lexington, Kentucky, \\ USA, ${ }^{2}$ Department of Population Health and Reproduction, School of Veterinary Medicine, University of California, \\ Davis, California, USA, ${ }^{3}$ College of Engineering, University of Kentucky, Lexington, Kentucky, USA and ${ }^{4}$ Department \\ of Molecular Biosciences, School of Veterinary Medicine, University of California, Davis, California, USA
}

Correspondence should be addressed to B A Ball; Email: b.a.ball@uky.edu

\begin{abstract}
In the latter half of gestation in the mare, progesterone concentrations decline to near undetectable levels while other $5 \alpha$-reduced pregnanes are elevated. Of these, $5 \alpha$-dihydroprogesterone and allopregnanolone have been reported to have important roles in either pregnancy maintenance or fetal quiescence. During this time, the placenta is necessary for pregnane metabolism, with the enzyme $5 \alpha$-reductase being required for the conversion of progesterone to $5 \alpha$-dihydroprogesterone. The objectives of this study were to assess the effects of a $5 \alpha$-reductase inhibitor, dutasteride on pregnane metabolism (pregnenolone, progesterone,

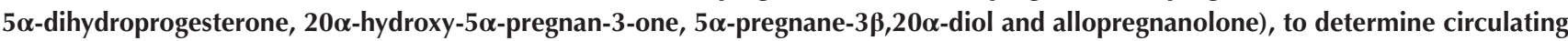
dutasteride concentrations and to assess effects of dutasteride treatment on gestational parameters. Pregnant mares $(n=5)$ received dutasteride $(0.01 \mathrm{mg} / \mathrm{kg} / \mathrm{day}, \mathrm{IM})$ and control mares $(n=4)$ received vehicle alone from 300 to 320 days of gestation or until parturition. Concentrations of dutasteride, pregnenolone, progesterone, $5 \alpha$-dihydroprogesterone, 20 $\alpha$-hydroxy-5 $\alpha$-pregnan-3-one, $5 \alpha$-pregnane-3 $3,20 \alpha$-diol, and allopregnanolone were evaluated via liquid chromatography-tandem mass spectrometry. Samples were analyzed as both days post treatment and as days prepartum. No significant treatment effects were detected in pregnenolone,

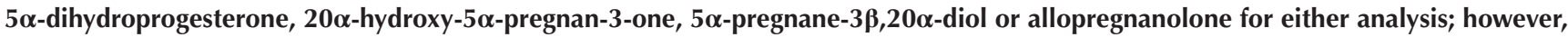
progesterone concentrations were increased $(P<0.05)$ sixfold in dutasteride-treated mares compared to control mares. Dutasteride concentrations increased in the treated mares, with a significant correlation $(P<0.05)$ between dutasteride concentrations and pregnenolone or progesterone concentrations. Gestational length and neonatal outcomes were not significantly altered in dutasteride-treated mares. Although $\mathbf{5} \alpha$-reduced metabolites were unchanged, these data suggest an accumulation of precursor progesterone with inhibition of $5 \alpha$-reductase, indicating the ability of dutasteride to alter progesterone metabolism.

Reproduction (2018) 155 251-258
\end{abstract}

\section{Introduction}

Progesterone (P4) is the primary hormone for pregnancy maintenance in most mammalian species (Challis et al. 2000, Conley 2016). Acting through the progesterone receptor (PR), P4 maintains myometrial quiescence and prevents premature parturition (Challis et al. 2000, Mendelson 2009). In contrast to other species, the mare has little detectable P4 in peripheral blood after midgestation (Short 1959, Holtan et al. 1991, Ousey et al. 2003, Scholtz et al. 2014). Although P4 levels rise dramatically during early pregnancy, analysis via mass spectrometry indicates that P4 concentrations begin to decline around 80 days of gestation and are undetectable by day 200 (Scholtz et al. 2014, Legacki et al. 2016b). Several pregnanes are present in high concentrations at this time, including $5 \alpha$-dihydroprogesterone (DHP),

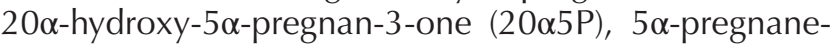

$3 \beta, 20 \alpha$-diol $\quad(\beta \alpha$-diol $) \quad$ and allopregnanolone (Chavatte et al. 1997, Ousey et al. 2003, 2005, Legacki et al. 2016a,b). Specifically, DHP is a direct metabolite of $\mathrm{P} 4$ and is known to bind the PR and maintain pregnancy in the absence of $\mathrm{P} 4$ (Challis et al. 2000, Chavatte-Palmer et al. 2000, Scholtz et al. 2014).

The key enzyme responsible for the conversion of P4 to DHP is $5 \alpha$-reductase. Steroid hormones with a $\Delta^{4}, 3$-oxo structure, including pregnanes, glucocorticoids and androgens can be $5 \alpha$-reduced by this enzyme (Russell \& Wilson 1994), and equine $5 \alpha$-reductase appears to act on $\Delta^{4}, 3$-oxo pregnenes (Raeside et al. 2015, Corbin et al. 2016). Of the two isoforms known to be present in the mare, $5 \alpha$-reductase type 1 is the predominant isoform in the endometrium and chorioallantois of pregnant mares (Scholtz et al. 2014, Legacki et al. 2017a,b). Once $5 \alpha$-reductase has metabolized P4 to DHP, DHP 
can be further metabolized into a variety of $5 \alpha$-reduced pregnanes including allopregnanolone. This hormone is a neuroactive steroid capable of binding $\mathrm{GABA}_{\mathrm{A}}$ receptors to enhance inhibitory neurotransmission (Belelli \& Lambert 2005) and is believed to have a sedative-like effect on the fetus (Madigan et al. 2012). In humans, horses and sheep, peripheral concentrations of allopregnanolone increase in both the maternal and fetal circulation, with levels peaking near term (Bicikova et al. 2002, Nguyen et al. 2003, Legacki et al. $2016 a, b)$. Other DHP metabolites include 20 $\alpha 5$ P and $\beta \alpha$-diol. The formation of these pregnanes is dependent upon enzyme metabolism within the uteroplacental tissue, and relative concentrations increase dramatically in mid-to-late gestation, similar to DHP (Legacki et al. 2016b). These pregnanes are of interest as they have been shown to activate the PR at prepartum peak concentrations in vitro (Legacki et al. 2016a), and they rely on $\mathrm{P} 4$ and DHP as steroidogenic precursors.

To demonstrate the importance of $5 \alpha$-reductase on pregnane metabolism and pregnancy, we evaluated the effects of dutasteride, a $5 \alpha$-reductase inhibitor in pregnant mares, which has been previously shown to inhibit $5 \alpha$-reductase in the horse in vitro (Corbin et al. 2016). Specifically, pregnane metabolism was monitored by measuring concentrations of specific pregnanes, and pregnancy outcome was evaluated in mares. It was hypothesized that administration of dutasteride to late pregnant mares would result in a decrease in DHP, $20 \alpha 5 \mathrm{P}, \beta \alpha$-diol and allopregnanolone. With a decrease in these bioactive pregnanes, we further hypothesized a reduced gestational length in dutasteride-treated mares compared to control mares. The objectives for the current study were to assess changes in target pregnanes (P4, P5, DHP, 20 $05 \mathrm{P}, \beta \alpha-$ diol and allopregnanolone) and neonatal outcome in pregnant mares treated with dutasteride compared to controls. Concentrations of dutasteride in the maternal and neonatal circulation, neonatal weight, as well as neonatal viability were determined.

\section{Materials and methods}

\section{Animal husbandry}

Nine healthy light-breed broodmares with a mean age of 9.7 years $( \pm 1.2$ year) were used in this study. Mares were maintained at the Maine Chance Farm, Department of Veterinary Science, University of Kentucky, Lexington, KY, and all experimental protocols were approved by the Institutional Animal Use and Care Committee at the University of Kentucky (Protocol \#2012-1067). Gestational age was determined relative to day of ovulation (Day 0). Pregnant mares were maintained on pasture and supplemented with grain, and water, hay, salt and trace minerals were available ad libitum. When parturition was suspected via determination of milk $\mathrm{pH}$ (Canisso et al. 2013), mares were moved to individual box stalls for the night to monitor parturition.

\section{Study design}

Pregnant mares were randomly assigned to treatment $(n=5)$ or $(n=4)$ control groups. Beginning on day 298 of gestation, jugular venous blood samples were taken daily in 10-mL heparinized tubes and 10-mL plain tubes (Becton, Dickinson and Company, Franklin Lakes, NJ, USA), and blood sampling continued through parturition. Blood samples were centrifuged at $1811 \mathrm{~g}$ for ten minutes, and plasma and serum were stored at $-20^{\circ} \mathrm{C}$ until analysis. Beginning at day 300 of gestation, treated mares received intramuscular (IM) injections of dutasteride (Aurum Pharmaceuticals; Franklin Park, NJ, USA) at $0.01 \mathrm{mg} / \mathrm{kg}$ body weight, in an ethanol/mygliol (Thermo Fisher Scientific; Warner Graham Company, Cockeysville, MD, USA) vehicle (60:40, ethanol:mygliol), and control mares received IM injections of vehicle alone. Dutasteride dosage was extrapolated from humans where the elimination halflife is known to be long (3-5 weeks) (Evans \& Goa 2003). Dutasteride or vehicle control administration continued daily until day 320 of gestation or until parturition. Upon mammary development, milk samples were monitored for $\mathrm{pH}$, to assess impending parturition. When milk pH neared 7.0, a FOAL ALERT sensor (Foal Alert. Inc., Acworth, GA, USA) was sutured to the vulva, per manufacturer's instructions. Immediately after parturition, blood was collected from the neonate and mare via jugular venipuncture. After foaling, weights of the neonate and mare were recorded.

\section{Steroid analysis}

Plasma concentrations of P5, P4, DHP, 20 $25 \mathrm{P}, \beta \alpha$-diol and allopregnanolone (Table 1) were determined via liquid chromatography-tandem mass spectrometry (LC/MS-MS). Samples were analyzed every other day beginning at day 298 of gestation and then daily for nine days prior to parturition. Pregnane concentrations were determined as previously reported with an accuracy $>90 \%$, precision $<15 \%$ and average limit of quantification of $0.33 \mathrm{ng} / \mathrm{mL}$ (Legacki et al. 2016b).

\section{Determination of circulating dutasteride concentrations}

Dutasteride concentrations were analyzed at the University of Kentucky Environmental Research Training Laboratory, utilizing a modified protocol (Contractor et al. 2013). In short, dutasteride was measured from serum with a Varian 410 auto sampler, Varian ProStar 210 pumps and a Varian $1200 \mathrm{~L}$ triple quadrupole mass spectrometer (Walnut Creek, CA, USA). This method utilized a Kinetex C18 column $(100 \times 2.1 \mathrm{~mm} \times 2.6 \mu \mathrm{m})$ (Phenomenex, Torrance, CA, USA), with mobile phase $A$ consisting of water with $0.1 \%$ formic acid and mobile phase B consisting of methanol with $0.1 \%$ formic acid. Ionization was achieved by electrospray ionization. Elution gradient (Table 2) and the reporting limit, quality controls (QC), ions, extraction efficiency, accuracy and precision (Table 3) were determined. The internal standard, dutasteride-13C6 (Clearsynth; Mississauga, ON, Canada), was dissolved in methanol at a working concentration of $100 \mathrm{ng} /$ $\mathrm{mL}$. Standards were made by dissolving dutasteride (Aurum Pharmaceuticals; Franklin Park, NJ, USA) in methanol at an initial concentration of $100,000 \mathrm{ng} / \mathrm{mL}$. Charcoal-stripped 
Table 1 Pregnane identification.

\begin{tabular}{|c|c|c|c|}
\hline Abbreviation used in this text & Chemical name & Trivial name & Alternative abbreviation \\
\hline P5 & $\begin{array}{l}\text { Pregn-5-ene-3 } \beta \text {-ol,20-one (a) } \\
3 \beta \text {-Hydroxy-5 } \alpha \text {-pregnen-20-one (b) } \\
3 \beta \text {-Hydroxy-5-pregnen-20-one (c) }\end{array}$ & Pregnenolone & \\
\hline P4 & $\begin{array}{l}\text { Pregn-4-ene-3,20-dione }(\mathrm{a}) \\
\text { 4-Pregnene-3,20-dione }(\mathrm{b}, \mathrm{c})\end{array}$ & Progesterone & \\
\hline $\mathrm{DHP}(\mathrm{a})$ & $5 \alpha$-Pregnan-3,20-dione $(\mathrm{a}, \mathrm{b}, \mathrm{c})$ & (5 $\alpha)$ Dihydroprogesterone & $5 \alpha \mathrm{DHP}(\mathrm{b}, \mathrm{c})$ \\
\hline $20 \propto 5 P(b)$ & $\begin{array}{l}5 \alpha \text {-Pregnan-20 } \alpha \text {-ol-3one }(\mathrm{a}) \\
20 \alpha \text {-Hydroxy-5 } \alpha \text {-pregnan-3-one }(\mathrm{b}, \mathrm{c})\end{array}$ & 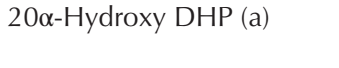 & $\begin{array}{l}20 \alpha \operatorname{DHP}(a) \\
20 \alpha 5 \alpha(c)\end{array}$ \\
\hline$\beta \alpha-\operatorname{diol}(b, c)$ & $\begin{array}{l}5 \alpha \text {-Pregnan- } 3 \beta, 20 \alpha \text {-diol (a) } \\
5 \alpha \text {-Pregnane- } 3 \beta, 20 \alpha \text {-diol }(b, c)\end{array}$ & $3 \beta, 20 \alpha$-Dihydroxy DHP (a) & $3 \beta, 20 \alpha \mathrm{DHP}(\mathrm{a})$ \\
\hline Allopregnanolone & $\begin{array}{l}5 \alpha \text {-Pregnan-3 } \alpha \text {-ol-20-dione (a) } \\
3 \alpha \text {-Hydroxy-5 } \alpha \text {-pregnan-20-one (b) }\end{array}$ & Allopregnanolone & $3 \alpha \mathrm{DHP}(\mathrm{a})$ \\
\hline
\end{tabular}

Pregnanes referenced in this paper along with a comparison of pregnane identifications among published articles. (a) Legacki et al. (2016a,b), (b) Ousey et al. (2005), (c) Schutzer et al. (1996).

gelding serum was used for the standard curve points, QCs and blanks. Seven standard points at 80, 50, 25, 10, 5, 0.5 and $0.1 \mathrm{ng} / \mathrm{mL}$ were used to generate the standard curve $\left(r^{2}=0.99\right)$. Quality controls were assessed at 35, 15 and $1 \mathrm{ng} /$ $\mathrm{mL}$, and triplicates were included of each for the two-batch assays. Each sample, QC and standard point were analyzed utilizing $1.0 \mathrm{~mL}$ of serum.

\section{Statistical analysis}

Analysis of endocrine data was conducted using two models. The first model examined endocrine changes between treated and control mares from Day 298 to 320 . This model excluded two mares (one control and one dutasteride-treated mare) as they foaled prior to Day 320 of gestation and therefore did not complete the treatment, and the biological decline of pregnanes in the three days prior to parturition would have confounded the results (Legacki et al. 2016b). In the second model, endocrine data were analyzed for the nine days prior to parturition with all mares included in the analysis. Endocrine data were analyzed with random-effects mixed model with mare as a random effect and time, treatment and time-by-treatment interactions as fixed effects. Data were transformed (square root or log transformation) as required and model validity was tested by examination of normal quantile plots of residuals. Comparisons between treatment groups at individual time points were made using the test-slice function of JMP to generate preplanned linear contrasts. Gestational data (gestation length, neonatal and placental weights) were subject to a nonparametric analysis with a Mann-Whitney test. Dutasteride concentrations were analyzed with regression plots of drug and individual pregnane concentrations. Analysis was conducted utilizing JMP software (JMP, version 12. SAS Institute Inc., Cary, NC, USA), and significance was set at $P<0.05$. Data are expressed as mean \pm S.E.M. unless otherwise stated.

\section{Results}

\section{Foaling outcome}

All mares in the study delivered viable foals; however, one of the foals from a control mare had a severe omphalophlebitis and a patent urachus and was humanely killed at 5 days of age. Gestational lengths, neonatal weight and neonatal weight as a proportion of mare weight were not different between dutasteridetreated and control mares (Table 4). Three of the dutasteride-treated mares retained their placenta beyond three hours postpartum, but no control mares retained their placenta. Median placental weights were greater $(P<0.05)$ in dutasteride-treated $(n=4)$ than those in control $(n=3)$ mares.

\section{Peripheral pregnane (P5 and P4) and 5 $\alpha$-reduced pregnane concentrations}

For the period between 298 and 320 days of gestation, pregnane concentrations were evaluated in alternate day samples. For P4, there was an effect of time $(P<0.0001)$ and a time by treatment interaction $(P=0.0003$; Fig. 1$)$, and P4 was higher $(P<0.05)$ in dutasteride-treated mares at Days 314, 316, 318 and 320 of gestation with a six-fold difference in P4 concentrations at Day 320. An effect of time $(P<0.01)$ was detected for P5, $20 \alpha 5 \mathrm{P}$ and $\beta \alpha$-diol, but there was no time, treatment or time-by-treatment effects on concentrations of DHP or allopregnanolone between Days 298 and 320 (Fig. 1). For the nine days preceding parturition, there was a time effect $(P<0.0001)$ on P5, DHP, 20 $\alpha 5$ P, $\beta \alpha$-diol and allopregnanolone with each of these pregnanes decreasing in the three days preceding parturition

Table 2 Elution gradient.

\begin{tabular}{lccc}
\hline Time & \%A & \% B & Flow \\
\hline 00:00 & 50 & 50 & 0.2 \\
00:30 & 50 & 50 & 0.2 \\
07:00 & 5 & 95 & 0.2 \\
09:00 & 5 & 95 & 0.2 \\
10:00 & 50 & 50 & 0.2 \\
18:00 & 50 & 50 & 0.2 \\
\hline
\end{tabular}

Mobile phase A consisted of water with $0.1 \%$ formic acid, and B consisted of methanol with $0.1 \%$ formic acid. Flow rate was $0.2 \mathrm{~mL} / \mathrm{min}$. 
Table 3 LC-MS/MS details.

\begin{tabular}{lcccccccc}
\hline Compound & Rt & Precursor ion & Daughter ions & $\begin{array}{c}\text { Reporting } \\
\text { limit }\end{array}$ & QCH CV/\%Acc & QCM CV/\%Acc & QCL CV/\%Acc & \%EE \\
\hline Dutasteride & 7.8 & 529 & $\mathbf{4 6 1 , 2 6 4 , 1 8 7}$ & 0.1 & $4.8 / 97.8$ & $5.9 / 97.6$ & $4 / 109.7$ & 83.6 \\
Dutasteride 13C6 & 7.8 & 535 & $\mathbf{4 6 7}, 270,187$ & 0.1 & NA & NA & NA & 86.7 \\
\hline
\end{tabular}

Compounds listed with retention time (Rt) in minutes, precursor ions, daughter ions, reporting limit, precision (\%CV) and accuracy (\%Acc) of quality controls (QCH, QCM and QCL) and extraction efficiency (\%EE). Daughter ions are listed in order of abundance, with the ion of quantification bolded. Reporting limit is listed in $\mathrm{ng} / \mathrm{mL}$ and was determined by the lowest standard visible with a linear curve. Precision and accuracy for QCH, QCM and QCL were determined by two runs containing triplicates of each QC. Percent accuracy was assessed by dividing the average QC values by the actual values and multiplying by 100. Extraction efficiency was calculated by dividing the area of the peak with extraction for dutasteride by the area of the peak without extraction for dutasteride and multiplied by 100 .

(Fig. 2). For P4, there were effects of time $(P<0.0001)$ and a time-by-treatment interaction $(P=0.01)$ such that $\mathrm{P} 4$ was greater $(P<0.05)$ in dutasteride-treated mares at Days $-7,-6,-5,-4,-3$ and -2 prior to parturition (Fig. 2). Neonatal pregnane concentrations were not different between foals from dutasteride-treated or control mares (Table 5).

\section{Dutasteride in circulation}

To assess circulating dutasteride concentrations, samples from treated mares were analyzed every four days, beginning from Day 298 and continuing through parturition (Fig. 3), along with a single sample from each of the treated foals to determine if dutasteride could cross the placenta. Two samples were selected at random from each control mare to include in the analysis. Overall, a time-dependent increase of dutasteride continued for the duration of the treatment. Two mares which foaled after administration of the final treatment exhibited a continual increase in dutasteride concentrations beyond Day 320. No dutasteride was detected in the control mares. In dutasteride-treated mares, there was a positive correlation between dutasteride concentrations and concentrations of P5 and P4; however, there was no significant correlation between dutasteride concentrations and either DHP or allopregnanolone (Fig. 4). Dutasteride concentrations were $22.7 \pm 6.7 \mathrm{ng} / \mathrm{mL}$ for the single sample taken from the foals of treated mares at birth, but none detected in control foals. Mean concentrations of dutasteride in neonatal circulation were $53 \%$ of maternal dutasteride concentrations, and neonatal and maternal concentrations of dutasteride were highly correlated at parturition $(r=0.98 ; P<0.0035)$ in mares treated with dutasteride.

\section{Discussion}

Administration of the $5 \alpha$-reductase inhibitor, dutasteride, to mares in late gestation did not significantly alter peripheral concentrations of DHP or its downstream metabolites (20 $\alpha 5 \mathrm{P}, \quad \beta \alpha$-diol, or allopregnanolone). However, administration of dutasteride did increase peripheral concentrations of the precursor, P4, sixfold in treated mares over controls by the end of treatment. Previously, Ousey and coworkers reported that administration of the related steroidal, $5 \alpha$-reductase inhibitor, finasteride, beginning at D300 of gestation also increased concentrations of P4 without decreasing concentrations of DHP (Ousey et al. 2001). Ousey and coworkers reported a reduced gestation length in mares treated with the $5 \alpha$-reductase inhibitor, finasteride, and although gestational lengths in the current study were not significantly reduced, dutasteride-treated mares did have numerically lower median gestation lengths. Both studies were limited by small animal numbers, as well as by the variable length of normal gestation in mares.

In the mare, a normal prepartum rise in circulating pregnanes occurs approximately 30 days before parturition, followed by a rapid decline in the days or hours prior to foaling (Seamans et al. 1979, Hamon et al. 1991, Legacki et al. 2016a,b). In the current study, changes in measured $5 \alpha$-reduced pregnanes in control and treated mares appeared similar to those previously reported (Legacki et al. 2016a,b) but dutasteride significantly increased P4, increasingly so as dutasteride concentrations rose. Dutasteride concentrations continued to increase beyond the end of treatment at D320 of gestation in treated mares that foaled later, and concentrations of the substrate, $\mathrm{P} 4$, also increased consistent with continued inhibition of $5 \alpha$-reductase in these mares.

The potential mechanism for reduced gestational lengths with inhibition of $5 \alpha$-reductase is unclear. There

Table 4 Gestational length and neonatal outcome.

\begin{tabular}{|c|c|c|c|c|c|c|}
\hline \multirow[b]{2}{*}{ Group } & \multirow[b]{2}{*}{ Gestation length (days) } & \multirow[b]{2}{*}{ Neonatal weight $(\mathrm{kg})$} & \multirow[b]{2}{*}{ Neonatal/mare weight $(\%)$} & \multirow[b]{2}{*}{ Placental weight (Kg) } & \multicolumn{2}{|c|}{ Neonatal gender } \\
\hline & & & & & Male & Female \\
\hline Dutasteride & $323(318,335)$ & $51(42,55)$ & $0.085(0.073,0.090)$ & $4.7(4.5,5.0)^{\mathrm{a}} ; n=4$ & 4 & 1 \\
\hline Control & $337(321,352)$ & $40(37,62)$ & $0.071(0.062,0.086)$ & $3.1(2.3,3.8)^{\mathrm{b}} ; n=3$ & 2 & 2 \\
\hline
\end{tabular}

Medians differ $(\mathrm{a}, \mathrm{b} P<0.05)$. Data represent the median with the 25 th and 75 th quartile indicated in parenthesis. 

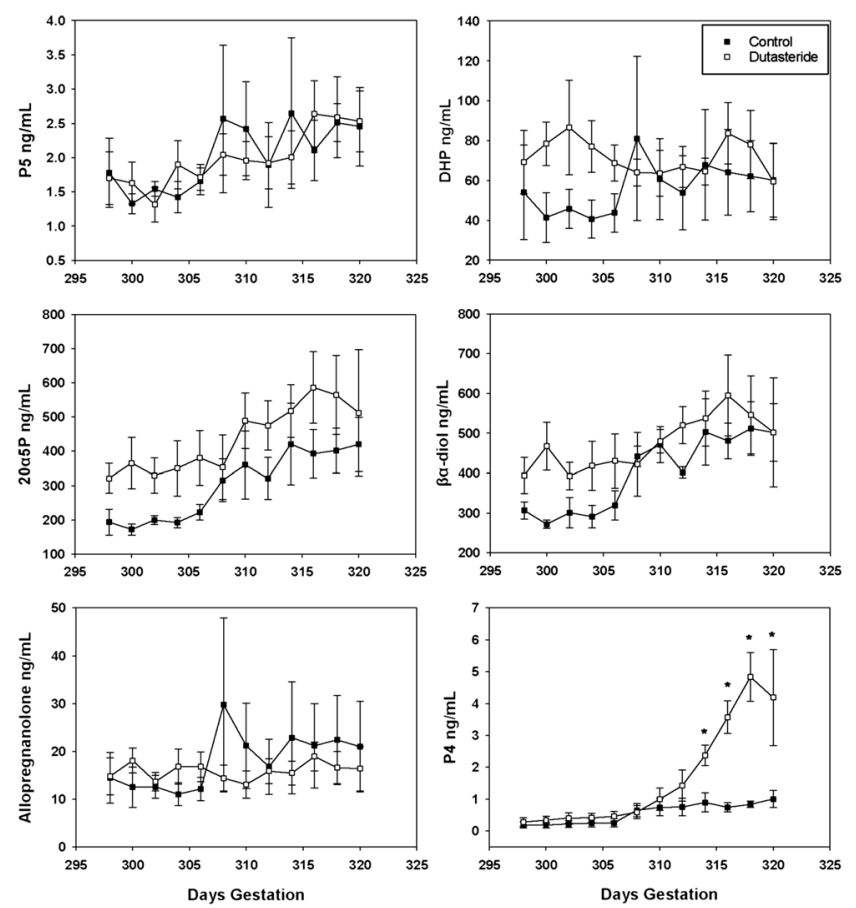

Figure 1 Plasma pregnane concentrations from before (day 298) and throughout treatment. Measured pregnane concentrations in control mares (solid squares) and dutasteride-treated mares (open squares) from 298 to 320 days of gestation. All graphs show days of gestation on the $x$-axis, with treatment beginning on day 300. Data represent the mean \pm 1 S.E.M. For pregnenolone (P5), $5 \alpha$-dihydroprogesterone

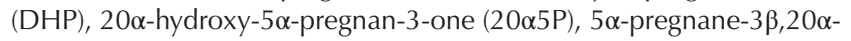
diol ( $\beta \alpha$-diol) and allopregnanolone no difference was noted between groups. For progesterone $(\mathrm{P} 4)$, significant differences $(P<0.05)$ are indicated with asterisks between groups for days 314 and 320 .

is a marked downregulation of $5 \alpha$-reductase activity and mRNA in the postpartum placenta of normal foaling mares compared to the placenta of mares at 10 months of gestation (Legacki et al. 2017b). This reduction in $5 \alpha$-reductase activity in the placenta is associated with a dramatic decline in $5 \alpha$-reduced pregnanes, including DHP, shortly before parturition (Legacki et al. 2016a). In the current study, reductions in circulating $5 \alpha$-reduced pregnanes were noted in both dutasteride-treated and control mares in the three days preceding parturition, but $5 \alpha$-reduced pregnanes were not different between groups in this period. Although normal parturition in the mare is associated with decreased $5 \alpha$-reductase activity in the placenta and a reduction in peripheral $5 \alpha$-reduced pregnanes, inhibition of $5 \alpha$-reductase with either finasteride or dutasteride did not achieve reductions in $5 \alpha$-reduced pregnanes or clear reductions in gestational length.

Although circulating concentrations of $5 \alpha$-reduced pregnanes were unchanged, elevations in progesterone associated with $5 \alpha$-reductase inhibition were noted in both the current study as well as the previous abstract from Ousey and coworkers. However, the potential role
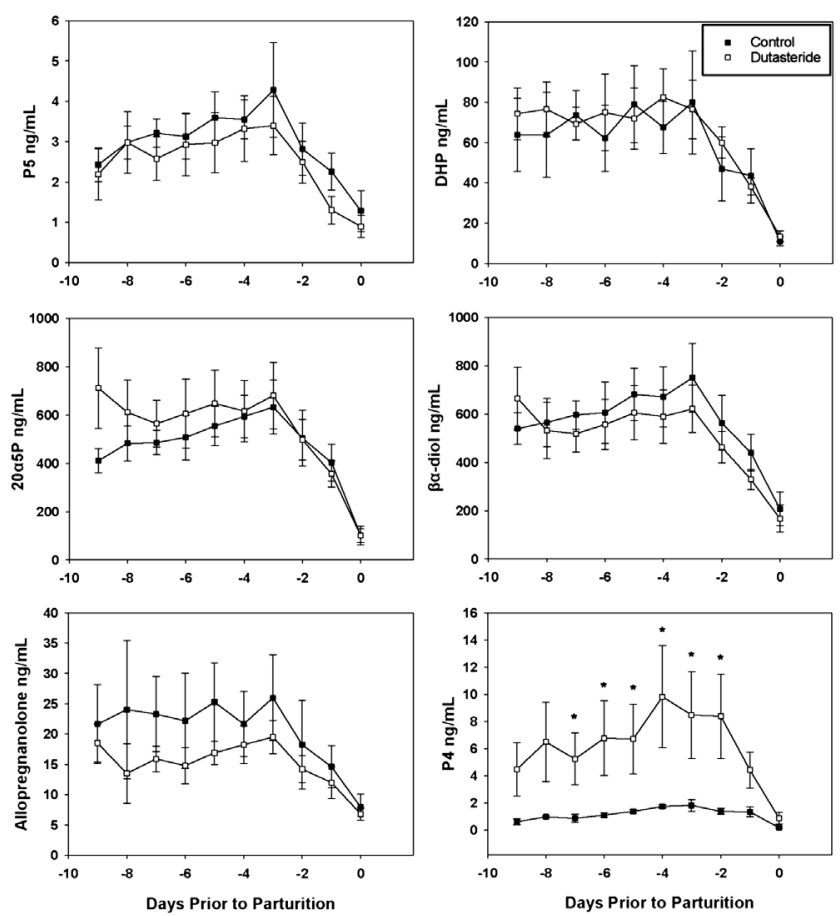

Figure 2 Plasma pregnane concentrations preceding parturition. Plasma pregnane concentrations in control mares (solid squares) and dutasteride-treated mares (open squares) for the last nine days of gestation. All graphs show days preceding parturition on the $x$-axis. Data represent \pm 1 S.E.M. For pregnenolone (P5),

$5 \alpha$-dihydroprogesterone (DHP), 20 $\alpha$-hydroxy-5 $\alpha$-pregnan-3-one

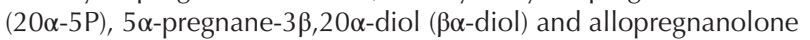
no difference was noted between groups. For progesterone (P4), significant differences $(P<0.05)$ are indicated with asterisks between groups for days -7 through -2 preceding parturition.

of elevations in $\mathrm{P} 4$ in the last month of gestation is unclear. Administration of the synthetic progestin, altrenogest, to mares in late gestation (>280 days) tended to shorten gestational length in mares (Neuhauser et al. 2008), and Alm and coworkers reported that administration of progesterone $(500 \mathrm{mg}$ daily) to pregnant mares beginning at 318 days of gestation significantly reduced gestational lengths (Alm et al. 1975). Unfortunately, no data on circulating concentrations of pregnanes are available in the Alm study, so it is not possible to know how circulating concentrations of progesterone and DHP were affected by their exogenous progesterone treatment. Effects of elevations in progesterone on reduced gestational length in mares, if any, remain poorly understood.

It is unclear whether altered placental expulsion and increased placental weights were associated with the recorded elevations in progesterone concentrations in dutasteride-treated mares. Treatment of mares with the synthetic progestin, altrenogest, during pregnancy did not alter placental retention time or weight (Shoemaker et al. 1989, Neuhauser et al. 2008). In cattle, Chew and coworkers (Chew et al. 1977) reported 
Table 5 Concentrations of pregnanes and dutasteride in neonatal foals.

\begin{tabular}{lccccc}
\hline Group & Pregnenolone & Progesterone & DHP & Allopregnanolone & Dutasteride \\
\hline Dutasteride & $725.5 \pm 140.2$ & $3.3 \pm 0.6$ & $21.8 \pm 2.4$ & $3.8 \pm 1.4$ & $22.7 \pm 6.7$ \\
Control & $834 \pm 308.6$ & $2.5 \pm 0.7$ & $24.6 \pm 8.7$ & $4 \pm 1.9$ & 0 \\
\hline
\end{tabular}

Concentrations of pregnanes and dutasteride $(\mathrm{ng} / \mathrm{mL})$ in neonatal foals born to dutasteride-treated and control mares. No significant differences were observed between groups. Data are mean \pm S.E.M.

increased peripartal progesterone concentrations in cattle with retained fetal membranes; however, most authors have not found an association between elevations in peripartal progesterone and retained placenta in cattle (Agthe \& Kolm 1975, Peter \& Bosu 1987, Wischral et al. 2001, Takagi et al. 2002).

The major interest in $5 \alpha$-reductase inhibitors has focused primarily on their use to reduce conversion of testosterone to the more biopotent $5 \alpha$-dihydrotestosterone in humans (Olsen et al. 2006, Aggarwal et al. 2010) with less interest in their ability to inhibit reduction of P4 to DHP. Dutasteride significantly reduced conversion of $\mathrm{P} 4$ to DHP in both mice (in vivo) and humans (in vitro) (Dong et al. 2001, Wiebe et al. 2006), as well as in the equine epididymis (Corbin et al. 2016) and equine embryo (Raeside et al. 2015). In human breast tissue, dutasteride resulted in not only a reduction of $5 \alpha$-reductase activity, but also significantly increased expression of the enzymes $3 \alpha$-hydroxysteroid

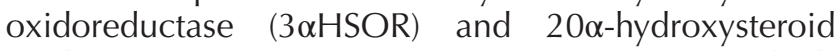
oxidoreductase (20 $\alpha \mathrm{HSOR})$ (Wiebe et al. 2006), which are necessary for metabolism of DHP to allopregnanolone and 20 55 P. This suggests dutasteride would decrease the levels of DHP and other downstream metabolites in treated mares and also potentially increase $20 \alpha 5 \mathrm{P}, \beta \alpha-$ diol and allopregnanolone concentrations. However, at the dosage used in the current study, concentrations of

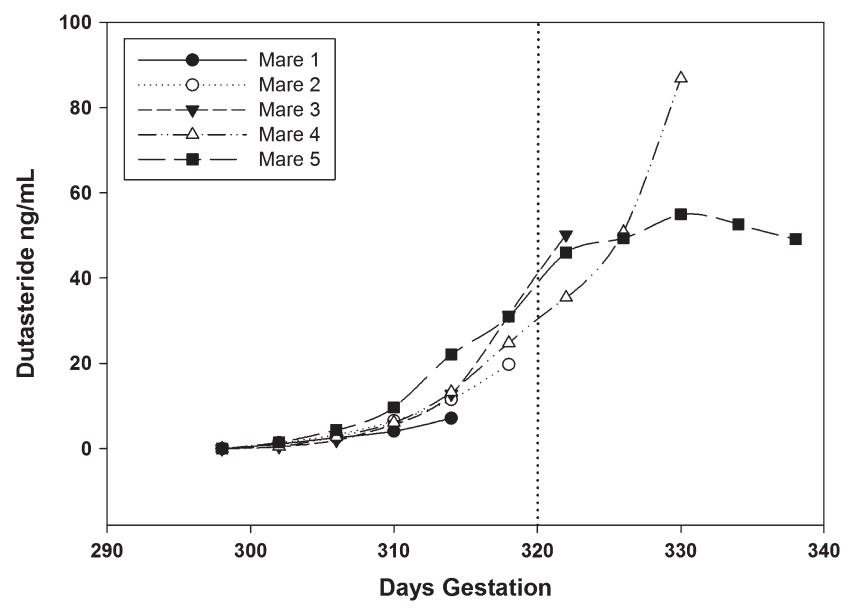

Figure 3 Dutasteride concentrations in treated mares. Graph shows the increase in dutasteride concentration during and post treatment for the five treated mares. The $x$-axis indicates days of gestation, and concentrations of dutasteride are shown along the $y$-axis in $\mathrm{ng} / \mathrm{mL}$. The vertical dotted line indicates the last day of treatment, with mares 1 and 2 foaling prior to the end of treatment. these $5 \alpha$-reduced pregnanes remained unchanged after administration of dutasteride. There was, however, a significant increase in P4 in dutasteride-treated mares that was consistent with a buildup of substrate due to at least partial enzyme inhibition.

In humans, dutasteride is reported to be 100 times as potent at inhibiting the type- 1 isoform of $5 \alpha$-reductase compared to finasteride (Olsen et al. 2006); therefore, dutasteride was expected to have a greater biopotency in this study when compared to the earlier report with finasteride in pregnant mares (Ousey et al. 2001). However, based upon in vitro observations using equine epididymis as the source of $5 \alpha$-reductase, both dutasteride and finasteride inhibit the type- 1 isoform of this enzyme with equal potency based on inhibition of the metabolism of P4 to DHP in vitro (Corbin et al. 2016). This is in contrast to potency differences reported in humans based upon inhibition of the reduction of testosterone to dihydrotestosterone by $5 \alpha$-reductase (Olsen et al. 2006). After intramuscular administration of dutasteride, concentrations of the inhibitor rose slowly and continued to rise in mares after cessation of administration at D320 for approximately 10 days. No
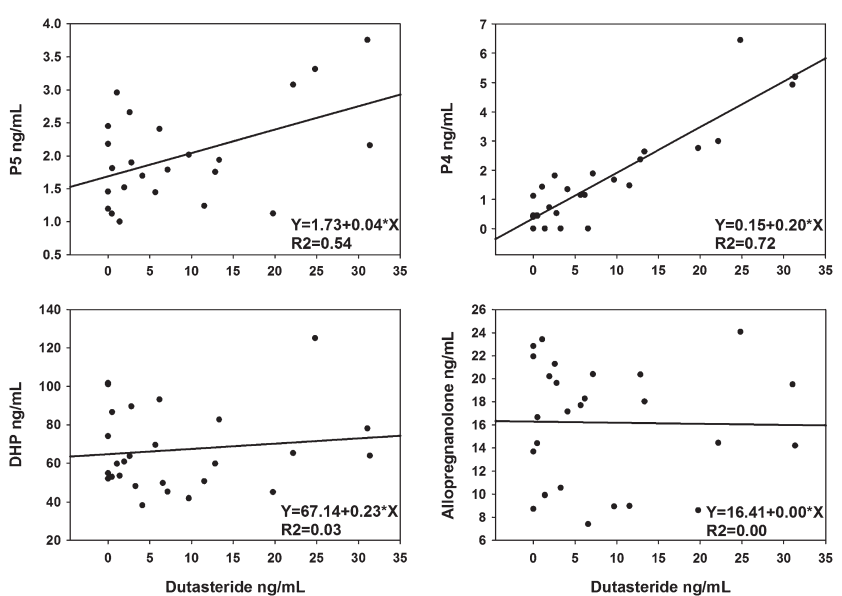

Figure 4 Regression plots for pregnanes and dutasteride concentrations. Measured concentrations of dutasteride and selected pregnanes in mares treated with dutasteride from 298 to 320 days of gestation. For each graph, pregnane concentration is indicated along the $y$-axis in $\mathrm{ng} / \mathrm{mL}$ and dutasteride concentration along the $x$-axis in $\mathrm{ng} / \mathrm{mL}$. Slope, intercept and coefficient of determination $\left(r^{2}\right)$ can be seen in the lower right corner. Pregnenolone (P5) and progesterone (P4) were significantly $(P<0.05)$ and positively associated with dutasteride concentrations, while $5 \alpha$-dihydroprogesterone (DHP) and allopregnanolone showed no association with dutasteride concentrations. 
data on half-life of dutasteride in the horse are available, but in humans, the cited terminal half-life is approximately three to five weeks (Gisleskog et al. 1999, Evans \& Goa 2003). For the current study, peak concentration of dutasteride in serum of treated mares was approximately $86 \mathrm{ng} / \mathrm{mL}(0.16 \mu \mathrm{M})$, well below the published $\mathrm{IC}_{50}$ of dutasteride for equine $5 \alpha$-reductase activity $(1.0 \mu \mathrm{M})$ (Corbin et al. 2016). In contrast, the $I_{50}$ for human type- 1 isoform of $5 \alpha$-reductase was much lower ( $7 \mathrm{nM}$ ) suggesting that the equine isoform of $5 \alpha$-reductase is not as readily inhibited by dutasteride (Azzouni et al. 2012). The slow release of dutasteride from the mygliol vehicle and the higher $I_{50}$ for dutasteride against equine $5 \alpha$-reductase may account for the observed lack of effect of dutasteride on DHP and other $5 \alpha$-reduced pregnane concentrations in treated mares. However, P4 concentrations were increased sixfold above those of vehicle-treated mares. Because DHP concentrations at this stage of gestation are much higher than P4 concentrations in pregnant mares (approximately 50:1), small changes in DHP concentrations (of $5-6 \mathrm{ng} / \mathrm{mL}$ ) due to inhibition of $5 \alpha$-reductase would not be expected to be detectable against high background concentrations of DHP. The relatively low concentrations of P4 are likely to be a far more sensitive indicator for inhibition of $5 \alpha$-reductase activity.

Based upon neonatal concentrations of dutasteride, this azasteroid crossed the equine placenta with neonatal concentrations approximately $50 \%$ of maternal concentrations in treated mares. Based upon neonatal concentrations of pregnanes, however, there did not appear to be an effect of dutasteride on fetal pregnane metabolism at these concentrations, as concentrations of P5, P4, DHP and allopregnanolone were not different in neonatal serum from treated and control groups.

Although $5 \alpha$-reductase catalyzes the direct reduction of $\mathrm{P} 4$ to DHP, an alternative pathway for synthesis of DHP from P5 by which equine $5 \alpha$-reductase directly

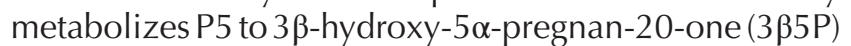
with subsequent oxidation to DHP has been postulated (Schutzer \& Holtan 1996, Schutzer et al. 1996). More recent reports indicate that pregnenolone is not a substrate for equine $5 \alpha$-reductase derived from either the epididymis (Corbin et al. 2016) or from early equine trophoblast (Raeside et al. 2015) and that this alterative pathway for synthesis of DHP is likely not important in pregnane metabolism by the equine placenta.

\section{Conclusions}

Administration of the $5 \alpha$-reductase inhibitor, dutasteride, to mares in late gestation increased maternal concentrations of P4 without detectable change in concentrations of DHP or other $5 \alpha$-reduced pregnanes (20 $\alpha 5$ P, $\beta \alpha$-diol or allopregnanolone). Dutasteride administration was also associated with increased placental weights postpartum and an apparent increase in retained fetal membranes. Although $5 \alpha$-reductase activity is reduced in normal mares around parturition, the effects of inhibition of $5 \alpha$-reductase on gestation length by administration of dutasteride to the mare remain unclear, and studies with larger animal numbers may be required to address potential effects of inhibition of $5 \alpha$-reductase on parturition in the mare.

\section{Declaration of interest}

The authors declare that there is no conflict of interest that could be perceived as prejudicing the impartiality of the research reported.

\section{Funding}

This work was supported by the Albert G Clay endowment and by the Markey Trust of the University of Kentucky as well as by the John P Hughes Endowment of the University of California, Davis.

\section{Acknowledgements}

The authors wish to thank Jackie Barr and Brandon Wheying for their assistance in sample collection and animal care which made this project possible. The authors also wish to express gratitude to the staff at Maine Chance farm for equipment set up and collaboration during this study.

\section{References}

Aggarwal S, Thareja S, Verma A, Bhardwaj TR \& Kumar M 2010 An overview on 5alpha-reductase inhibitors. Steroids 75 109-153. (https:// doi.org/10.1016/j.steroids.2009.10.005)

Agthe O \& Kolm HP 1975 Oestrogen and progesterone levels in the blood plasma of cows with normal parturition or with a retained placenta. Journal of Reproduction and Fertility 43 163-166. (https://doi. org/10.1530/jrf.0.0430163)

Alm CC, Sullivan JJ \& First NL 1975 The effect of a corticosteroid (dexamethasone), progesterone, oestrogen and prostaglandin F2alpha on gestation length in normal and ovariectomized mares. Journal of Reproduction and Fertility 23 (Supplement) 637-640.

Azzouni F, Godoy A, Li Y \& Mohler J 2012 The 5 alpha-reductase isozyme family: a review of basic biology and their role in human diseases. Advances in Urology 2012 530121. (https://doi. org/10.1155/2012/530121)

Belelli D \& Lambert JJ 2005 Neurosteroids: endogenous regulators of the GABA(A) receptor. Nature Reviews Neuroscience 6 565-575. (https:// doi.org/10.1038/nrn1703)

Bicikova M, Klak J, Hill M, Zizka Z, Hampl R \& Calda P 2002 Two neuroactive steroids in midpregnancy as measured in maternal and fetal sera and in amniotic fluid. Steroids 67 399-402. (https://doi.org/10.1016/ S0039-128X(01)00196-9)

Canisso IF, Ball BA, Troedsson MH, Silva ES \& Davolli GM 2013 Decreasing $\mathrm{pH}$ of mammary gland secretions is associated with parturition and is correlated with electrolyte concentrations in prefoaling mares. Veterinary Record 173 218. (https://doi.org/10.1136/vr.101658)

Challis JRG, Matthews SG, Gibb W \& Lye SJ 2000 Endocrine and paracrine regulation of birth at term and preterm. Endocrine Reviews 21 514-550. (https://doi.org/10.1210/edrv.21.5.0407)

Chavatte P, Holtan D, Ousey JC \& Rossdale PD 1997 Biosynthesis and possible biological roles of progestagens during equine pregnancy and 
in the newborn foal. Equine Veterinary Journal 29 89-95. (https://doi. org/10.1111/j.2042-3306.1997.tb05084.x)

Chavatte-Palmer P, Duchamp G, Palmer E, Ousey JC, Rossdale PD \& Lombes M 2000 Progesterone, oestrogen and glucocorticoid receptors in the uterus and mammary glands of mares from mid- to late gestation. Journal of Reproduction and Fertility Supplement 56661-672.

Chew BP, Keller HF, Erb RE \& Malven PV 1977 Periparturient concentrations of prolactin, progesterone and the estrogens in blood plasma of cows retaining and not retaining fetal membranes1,2. Journal of Animal Science 44 1055-1060. (https://doi.org/10.2527/jas1977.4461055x)

Conley AJ 2016 Review of the reproductive endocrinology of the pregnant and parturient mare. Theriogenology 86 355-365. (https://doi. org/10.1016/j.theriogenology.2016.04.049)

Contractor P, Kurani H, Guttikar S \& Shrivastav PS 2013 Reliable and sensitive determination of dutasteride in human plasma by liquid chromatography-tandem mass spectrometry. Biomedical Chromatography 27 1168-1176. (https://doi.org/10.1002/bmc.2923)

Corbin CJ, Legacki EL, Ball BA, Scoggin KE, Stanley SD \& Conley AJ 2016 Equine 5alpha-reductase activity and expression in epididymis. Journal of Endocrinology 231 23-33. (https://doi.org/10.1530/JOE-16-0175)

Dong E, Matsumoto K, Uzunova V, Sugaya I, Takahata H, Nomura H, Watanabe H, Costa E \& Guidotti A 2001 Brain 5alphadihydroprogesterone and allopregnanolone synthesis in a mouse model of protracted social isolation. PNAS 98 2849-2854. (https://doi. org/10.1073/pnas.051628598)

Evans HC \& Goa KL 2003 Dutasteride. Drugs and Aging 20 905-916.

Gisleskog PO, Hermann D, Hammarlund-Udenaes M \& Karlsson MO 1999 The pharmacokinetic modelling of Gl198745 (dutasteride), a compound with parallel linear and nonlinear elimination. British Journal of Clinical Pharmacology 47 53-58. (https://doi.org/10.1046/j.13652125.1999.00843.x)

Hamon M, Clarke SW, Houghton E, Fowden AL, Silver M, Rossdale PD, Ousey JC \& Heap RB 1991 Production of 5 alpha-dihydroprogesterone during late pregnancy in the mare. Journal of Reproduction and Fertility 44 529-535.

Holtan DW, Houghton E, Silver M, Fowden AL, Ousey J \& Rossdale PD 1991 Plasma progestagens in the mare, fetus and newborn foal. Journal of Reproduction and Fertility 44 517-528.

Legacki EL, Corbin CJ, Ball BA, Wynn M, Loux S, Stanley SD \& Conley AJ 2016a Progestin withdrawal at parturition in the mare. Reproduction 152 323-331. (https://doi.org/10.1530/REP-16-0227)

Legacki EL, Scholtz EL, Ball BA, Stanley SD, Berger T \& Conley AJ $2016 b$ The dynamic steroid landscape of equine pregnancy mapped by mass spectrometry. Reproduction 151 421-430. (https://doi.org/10.1530/REP15-0547)

Legacki EL, Ball BA, Corbin CJ, Loux SC, Scoggin KE, Stanley SD \& Conley AJ 2017a Equine fetal adrenal, gonadal and placental steroidogenesis. Reproduction 154 445-454. (https://doi.org/10.1530/ REP-17-0239)

Legacki EL, Corbin CJ, Ball BA, Scoggin K, Stanley SD \& Conley A 2017 b Steroidogenic enzyme activities in the pre- and post-parturient equine placenta. Reproduction 155 51-59. (https://doi.org/10.1530/rep-170472)

Madigan JE, Haggettt EF, Pickles KJ, Conley A, Stanley S, Moeller B, Toth B \& Aleman M 2012 Allopregnanolone infusion induced neurobehavioural alterations in a neonatal foal: is this a clue to the pathogenesis of neonatal maladjustment syndrome? Equine Veterinary Journal $\mathbf{4 4}$ 109-112. (https://doi.org/10.1111/j.2042-3306.2011.00504.x)

Mendelson CR 2009 Minireview: fetal-maternal hormonal signaling in pregnancy and labor. Molecular Endocrinology 23 947-954. (https://doi. org/10.1210/me.2009-0016)

Neuhauser S, Palm F, Ambuehl F \& Aurich C 2008 Effects of altrenogest treatment of mares in late pregnancy on parturition and on neonatal viability of their foals. Experimental and Clinical Endocrinology and Diabetes 116 423-428. (https://doi.org/10.1055/s-2008-1065367)

Nguyen PN, Billiards SS, Walker DW \& Hirst JJ 2003 Changes in 5alpha-pregnane steroids and neurosteroidogenic enzyme expression in the perinatal sheep. Pediatric Research 53 956-964. (https://doi. org/10.1203/01.PDR.0000064905.64688.10)

Olsen EA, Hordinsky M, Whiting D, Stough D, Hobbs S, Ellis ML, Wilson T \& Rittmaster RS 2006 The importance of dual 5alpha- reductase inhibition in the treatment of male pattern hair loss: results of a randomized placebo-controlled study of dutasteride versus finasteride. Journal of the American Academy of Dermatology 55 1014-1023. (https://doi.org/10.1016/j.jaad.2006.05.007)

Ousey JC, Rossdale PD, Palmer L, Grainger L, Houghton E \& Fowden AL 2001 Effect of 5a-reductase blockade on progestagen metabolism and parturition in mares. Journal of Reproduction and Fertility 27 11-12.

Ousey JC, Forhead AJ, Rossdale PD, Grainger L, Houghton E \& Fowden AL 2003 Ontogeny of uteroplacental progestagen production in pregnant mares during the second half of gestation. Biology of Reproduction 69 540-548. (https://doi.org/10.1095/biolreprod.102.013292)

Ousey JC, Houghton E, Grainger L, Rossdale PD \& Fowden AL 2005 Progestagen profiles during the last trimester of gestation in Thoroughbred mares with normal or compromised pregnancies. Theriogenology 63 1844-1856.

Peter AT \& Bosu WT 1987 Peripartal endocrine changes associated with retained placenta in dairy cows. Theriogenology 28 383-394. (https:// doi.org/10.1016/0093-691X(87)90026-4)

Raeside JI, Christie HL \& Betteridge KJ 2015 5Alpha-reduced steroids are major metabolites in the early equine embryo proper and its membranes. Biology of Reproduction 93 77. (https://doi.org/10.1095/ biolreprod.115.131680)

Russell DW \& Wilson JD 1994 Steroid 5 alpha-reductase: two genes/ two enzymes. Annual Review of Biochemistry 63 25-61. (https://doi. org/10.1146/annurev.bi.63.070194.000325)

Scholtz EL, Krishnan S, Ball BA, Corbin CJ, Moeller BC, Stanley SD, McDowell KJ, Hughes AL, McDonnell DP \& Conley AJ 2014 Pregnancy without progesterone in horses defines a second endogenous biopotent progesterone receptor agonist, 5alpha-dihydroprogesterone. PNAS 111 3365-3370. (https://doi.org/10.1073/pnas.1318163111)

Schutzer WE \& Holtan DW 1996 Steroid transformations in pregnant mares: metabolism of exogenous progestins and unusual metabolic activity in vivo and in vitro. Steroids 61 94-99. (https://doi.org/10.1016/0039128X(95)00199-Z)

Schutzer WE, Kerby JL \& Holtan DW 1996 Differential effect of trilostane on the progestin milieu in the pregnant mare. Journal of Reproduction and Fertility 107 241-248. (https://doi.org/10.1530/jrf.0.1070241)

Seamans KW, Harms PG, Atkins DT \& Fleeger JL 1979 Serum levels of progesterone, 5 alpha-dihydroprogesterone and hydroxy- 5 alphapregnanones in the prepartum and postpartum equine. Steroids 33 55-63. (https://doi.org/10.1016/S0039-128X(79)80006-9)

Shoemaker CF, Squires EL \& Shideler RK 1989 Safety of altrenogest in pregnant mares and on health and development of offspring. Journal of Equine Veterinary Science 9 69-72. (https://doi.org/10.1016/S07370806(89)80030-9)

Short RV 1959 Progesterone in blood. IV. Progesterone in the blood of mares. Journal of Endocrinology 19 207-210. (https://doi.org/10.1677/ joe.0.0190207)

Takagi M, Fujimoto S, Ohtani M, Miyamoto A, Wijagunawardane MP, Acosta TJ, Miyazawa K \& Sato K 2002 Bovine retained placenta: hormonal concentrations in fetal and maternal placenta. Placenta $\mathbf{2 3}$ 429-437. (https://doi.org/10.1053/plac.2002.0824)

Wiebe JP, Souter L \& Zhang G 2006 Dutasteride affects progesterone metabolizing enzyme activity/expression in human breast cell lines resulting in suppression of cell proliferation and detachment. Journal of Steroid Biochemistry and Molecular Biology 100 129-140. (https://doi. org/10.1016/j.jsbmb.2006.03.010)

Wischral A, Verreschi IT, Lima SB, Hayashi LF \& Barnabe RC 2001 Preparturition profile of steroids and prostaglandin in cows with or without foetal membrane retention. Animal Reproduction Science 67 181-188. (https://doi.org/10.1016/S0378-4320(01)00119-1)

Received 22 June 2017

First decision 14 August 2017

Revised manuscript received 30 November 2017

Accepted 11 January 2018 